\title{
The association between premorbid beta blocker exposure and mortality in sepsis-a systematic review
}

\author{
Kaiquan Tan ${ }^{1}$, Martin Harazim ${ }^{4}$, Benjamin Tang ${ }^{1,3}$, Anthony Mclean ${ }^{1,2}$ and Marek Nalos ${ }^{1,2,4^{*}}$ (D)
}

\begin{abstract}
Background: The effect of premorbid $\beta$-blocker exposure on clinical outcomes in patients with sepsis is not well characterized. We aimed to examine the association between premorbid $\beta$-blocker exposure and mortality in sepsis.

Methods: EMBase, MEDLINE, and Cochrane databases were searched for all studies of premorbid $\beta$-blocker and sepsis. The search was last updated on 22 June 2019. Two reviewers independently assessed, selected, and abstracted data from studies reporting chronic $\beta$-blocker use prior to sepsis and mortality. Main data extracted were premorbid $\beta$-blocker exposure, mortality, study design, and patient data. Two reviewers independently assessed the risk of bias and quality of evidence.
\end{abstract}

Results: In total, nine studies comprising 56,414 patients with sepsis including 6576 patients with premorbid exposure to $\beta$-blockers were eligible. For the primary outcome of mortality, two retrospective studies reported adjusted odds ratios showing a reduction in mortality with premorbid $\beta$-blocker exposure. One study showed that premorbid $\beta$-blocker exposure decreases mortality in patients with septic shock. Another study showed that continued $\beta$-blockade during sepsis is associated with decreased mortality.

Conclusion: This systematic review suggests that $\beta$-blocker exposure prior to sepsis is associated with reduced mortality. There was insufficient data to conduct a bona fide meta-analysis. Whether the apparent reduction in mortality may be attributed to the mitigation of catecholamine excess is unclear.

Trial registration: PROSPERO, CRD42019130558 registered June 12, 2019.

Keywords: Sepsis, Mortality, Beta blockers, Systematic review

\section{Introduction}

The Sepsis-3 consensus defines sepsis as a life-threatening organ dysfunction caused by a dysregulated host response to infection [1]. While our understanding of sepsis pathophysiology is increasing, controversies in haemodynamic management persist [2, 3]. The most recent surviving sepsis guidelines recommend noradrenaline as the first-choice vasopressor because of its vasopressor and positive inotropic properties [strong recommendation, moderate quality of evidence [4]]. In contrast, the concept of 'decatecholamisation' emerged

\footnotetext{
* Correspondence: mareknalos@gmail.com

${ }^{1}$ Nepean Clinical School, Sydney Medical School, University of Sydney, Penrith, Australia

${ }^{2}$ Department of Intensive Care Medicine, Nepean Hospital, Penrith, Australia Full list of author information is available at the end of the article
}

in the last decade stemming from the recognized negative effects of catecholamines in sepsis $[3,5,6]$. Interestingly, the $\beta$-adrenergic blockade has emerged as a possible treatment option for blunting the adrenergic response in early sepsis with potential effects on the modulation of cardiogenic, metabolic, immunologic, and coagulopathic derangements in sepsis [7].

Early administration of the short-acting $\beta$-blocker esmolol in a recent trial showed a reduction in 28-day sepsis mortality $[8,9]$. Furthermore, some studies have suggested a benefit of premorbid $\beta$-blocker exposure on sepsis outcomes [10, 11]. Multiple systematic reviews have since concluded that there is limited preliminary evidence for the use of $\beta$-blockers during sepsis [12-14], while others are skeptical [15]. However, to date, no published systematic review exists on the effects of 
premorbid $\beta$-blocker exposure on sepsis outcomes, including mortality. Therefore, we set out to systematically examine the evidence from all human studies on premorbid $\beta$-blocker exposure and sepsis.

\section{Materials and methods}

This study follows the Meta-analysis Of Observational Studies in Epidemiology (MOOSE) guidelines [16] and was registered with the international prospective register of systematic reviews (PROSPERO; CRD 42019130558). The MOOSE checklist is appended as Additional file 1: Table S1.

\section{Data sources and searches}

Three databases, EMBase, MEDLINE, and Cochrane were searched on 30 January 2019 for records dating from database conception to the date of search that was last updated on 22 June 2019. The search was only limited to human research. Duplicates were removed using the Ovid platform and checked for any incorrect removal. Hand searching from reference lists was also performed. The full search strategy is appended as Additional file 4: Figure S1.

\section{Study selection}

Inclusion criteria for this review were guided by the 'Patient, Population, or Problem, Intervention, Comparison, Outcome, Study Design or Setting' (PICOS) framework [17] (Table 1). Patients exposed to $\beta$-blockers prior to an episode of sepsis or septic shock and were cared for in the emergency department (ED) or intensive care unit (ICU) were included in this review. Observational studies were eligible. Excluded were case studies/small series $(<20$ patients overall $)$ and review articles. The abstracts were assessed by two investigators (KT, MH) independently, and disagreements were resolved with a third investigator $(\mathrm{MN})$.

\section{Data extraction and quality assessment}

Data from eligible studies were independently extracted by two investigators (KT, MH). Where required, study authors were contacted directly to kindly provide

Table 1 'PICOS' approach for selecting clinical studies in the systematic search. PICOS Patient, Population, or Problem, Intervention, Comparison, Outcome, Study Design or Setting

\begin{tabular}{ll}
\hline PICOS & Study characteristics \\
\hline 1. Participants & Patients with sepsis and/or septic shock \\
2. Intervention & Premorbid exposure to beta blockers \\
3. Comparison & No premorbid exposure to beta blockers \\
4. Outcomes & Mortality \\
5. Study design & Prospective observational or retrospective \\
& cohort studies \\
\hline
\end{tabular}

missing research data. The Risk Of Bias In Non-randomized Studies - of Interventions (ROBINS-I) tool [18] was used to independently assess $(\mathrm{KQ}, \mathrm{MH})$ the quality of studies.

\section{Data synthesis and analysis}

Adjusted outcome data were combined using the inverse variance method [19]. Heterogeneity between studies was measured by Higgin's and Thomson's $I^{2}$ [20]. Statistical analyses were performed using Review Manager version 5.3 (Copenhagen: The Cochrane Collaboration, 2014)

\section{Results}

\section{Study selection}

The initial search returned 2128 abstracts, all in English. Two thousand sixty-four abstracts were manually screened after removal of 64 duplicates. After screening, 16 studies were initially selected for data extraction. Where required, the corresponding authors were contacted to obtain necessary data for statistical analysis. Seven studies were excluded for not meeting all inclusion criteria. The list of studies excluded is appended (Additional file 2: Table S2). Overall, a total of nine studies were found to be eligible, comprising 56,414 patients with sepsis, including 6576 patients with premorbid exposure to $\beta$-blockers (Fig. 1).

\section{Characteristics and type of studies}

All studies were retrospective cohort studies, and the data were collected between 1999 and 2017.

The study populations described patients with sepsis, severe sepsis, or septic shock in an ED [21] or ICU [10, 11, 21-26] setting. The definitions of sepsis, severe sepsis, septic shock, and premorbid $\beta$-blocker exposure varied slightly across the studies, but were reasonable and comparable to current definitions [1]. Two studies [10, 27] included patients with sepsis, severe sepsis, and septic shock, while seven studies [11, 21-26] included patients with severe sepsis and/or septic shock. One study (Alsolamy et al.) included patients $\geq 14$ years of age; all other studies included adult (18 years and above) patients. Four studies by Sharma et al., de Roquetaillade et al., Alsolamy et al., and Al-Qadi et al. were reported as conference abstracts [22-25]. The characteristics of the studies are appended (Table 2).

\section{Risk of bias assessment}

All observational studies of premorbid medication use are at risk of bias because of confounding. Five studies included in this review [10, 11, 24, 26, 27] were judged to be of moderate risk of bias for the primary outcome of mortality as they reported adjustment of confounding variables via statistical analysis. Four studies [21-23, 25] 

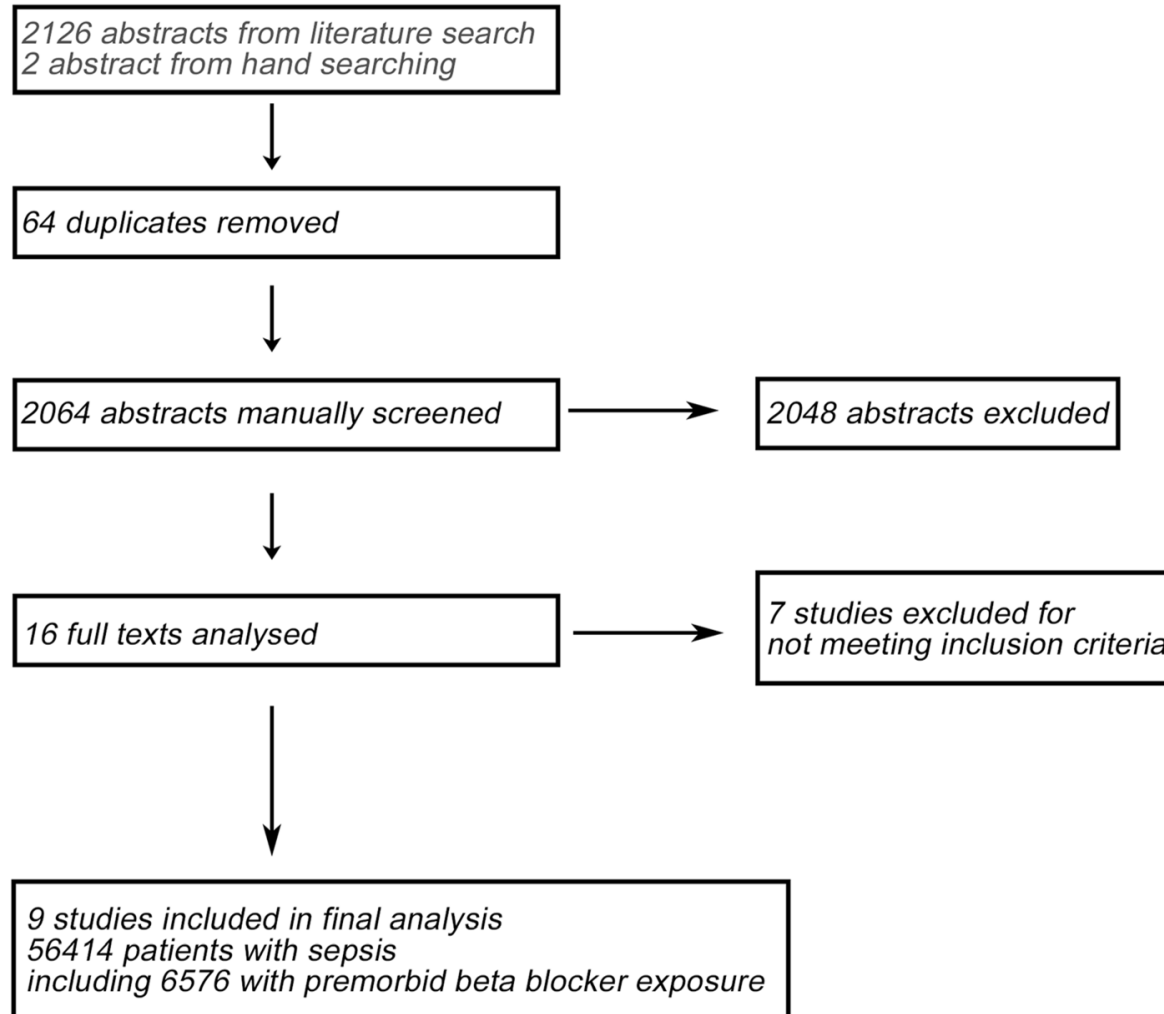

Fig. 1 Flow diagram of the study selection process

were judged as having serious risk of bias due to confounding as the authors did not perform statistical analysis to correct for confounders. The risk of bias assessment using ROBINS-1 tool for each trial is appended (Additional file 5: Figure S2) with reasonings attached (Additional file 3: Table S3).

\section{Primary outcome: mortality}

The smallest study by Contenti et al. included 260 sepsis patients. Results from that study showed a non-significant decrease in 28 -day mortality ( $35 \%$ vs $49 \%, p=0.08$; Table 3). Using multivariate logistic regression, three studies by Singer et al., Macchia et al., and Hsieh et al. reported mortality data as adjusted odds ratios $[10,11$, 27]. Singer et al. reported a decrease in hospital mortality in patients with severe sepsis and septic shock $(\mathrm{aOR}=$ 0.69; 95\% CI [0.62, 0.77]; Table 3). Subgroup analysis between cardioselective $\beta$-blockers and non-selective $\beta$ blockers showed that non-selective $\beta$-blockers were associated with lower hospital mortality, adjusted OR for non-selective $\beta$-blockers $(\mathrm{aOR}=0.59 ; 95 \%$ CI $[0.49$, $0.71])$ compared to cardioselective $\beta$-blockers $(\mathrm{aOR}=$ 0.73 ; $95 \%$ CI $[0.65,0.82])$. Overall mortality rate for cardioselective $\beta$-blocker users was higher, cardioselective $\beta$-blocker users vs. non-selective $\beta$-blocker users $(\mathrm{aOR}=$ 1.23 ; $95 \%$ CI [1.11-1.36]). Hospital mortality was also reduced across all age groups: between ages 65 and 74 $(\mathrm{aOR}=0.64 ; 95 \% \mathrm{CI}[0.52,0.80])$, between ages 75 and $84 \quad(\mathrm{aOR}=0.69 ; 95 \% \mathrm{CI}[0.58,0.83])$, and above 85 $(\mathrm{aOR}=0.73 ; 95 \%$ CI $[0.60,0.90])$.

Macchia et al. reported a significant decrease in 28day mortality in patients with sepsis $(\mathrm{aOR}=0.81 ; 95 \% \mathrm{CI}$ [0.68-0.97]; $p=0.025$; Table 3). Subgroup analysis investigating the effect of age, gender, organ dysfunction, and previous comorbidities did not alter the results. Adjustment for previous medication used including calcium channel blockers, amiodarone, angiotensin-convertingenzyme inhibitors, diuretics, or any nonsteroidal anti-inflammatory drugs also did not alter the results. The authors also conducted a propensity matching analysis, which led to similar results $(\mathrm{OR}=0.72$; 95\% CI $[0.57-$ 0.91]; $p=0.04$ ).

The study by Hsieh et al. showed that premorbid $\beta$ blocker exposure was not associated with a significant decrease in hospital mortality in patients with sepsis and septic shock $(\mathrm{aOR}=0.89 ; 95 \% \mathrm{CI}[0.76,1.04] ; p=$ 0.1484; Table 3). However, subgroup analysis of patients with septic shock showed that premorbid $\beta$ blocker exposure was significantly associated with decreased hospital mortality $(\mathrm{aOR}=0.68 ; 05 \%$ CI $[0.56$, 0.82 ]; $p=0.0001)$. In patients without septic shock, premorbid $\beta$-blocker exposure was associated with 


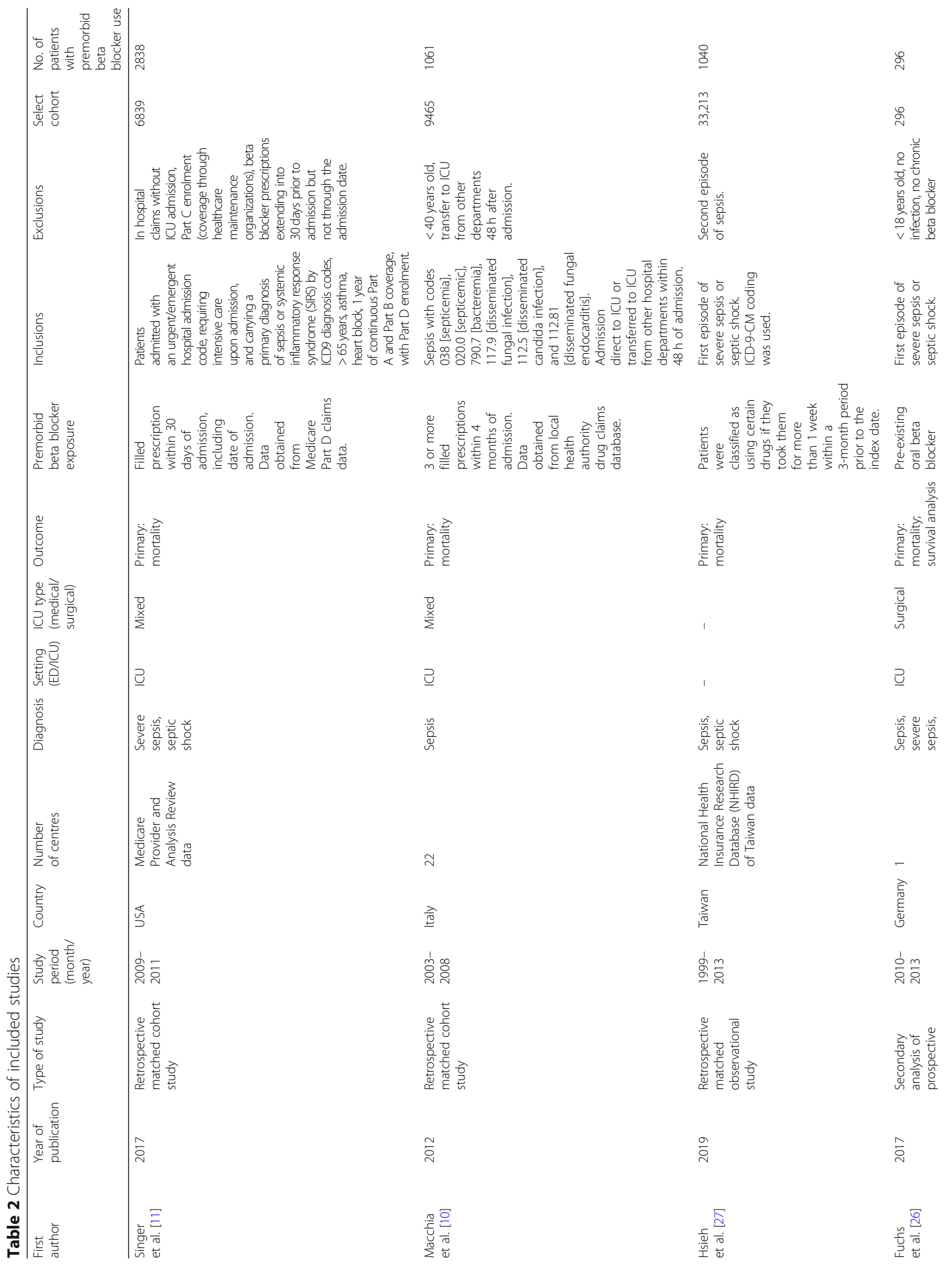




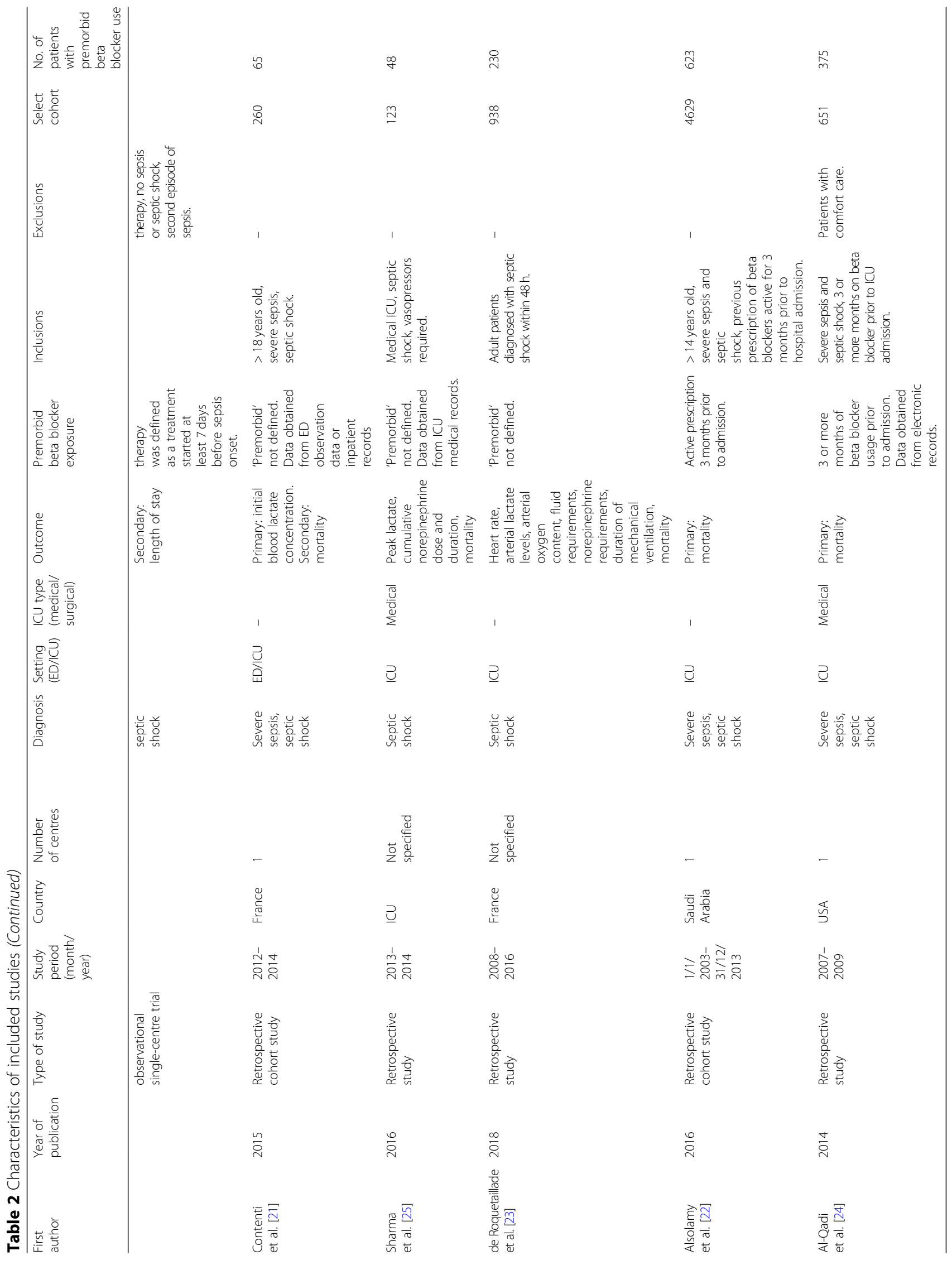




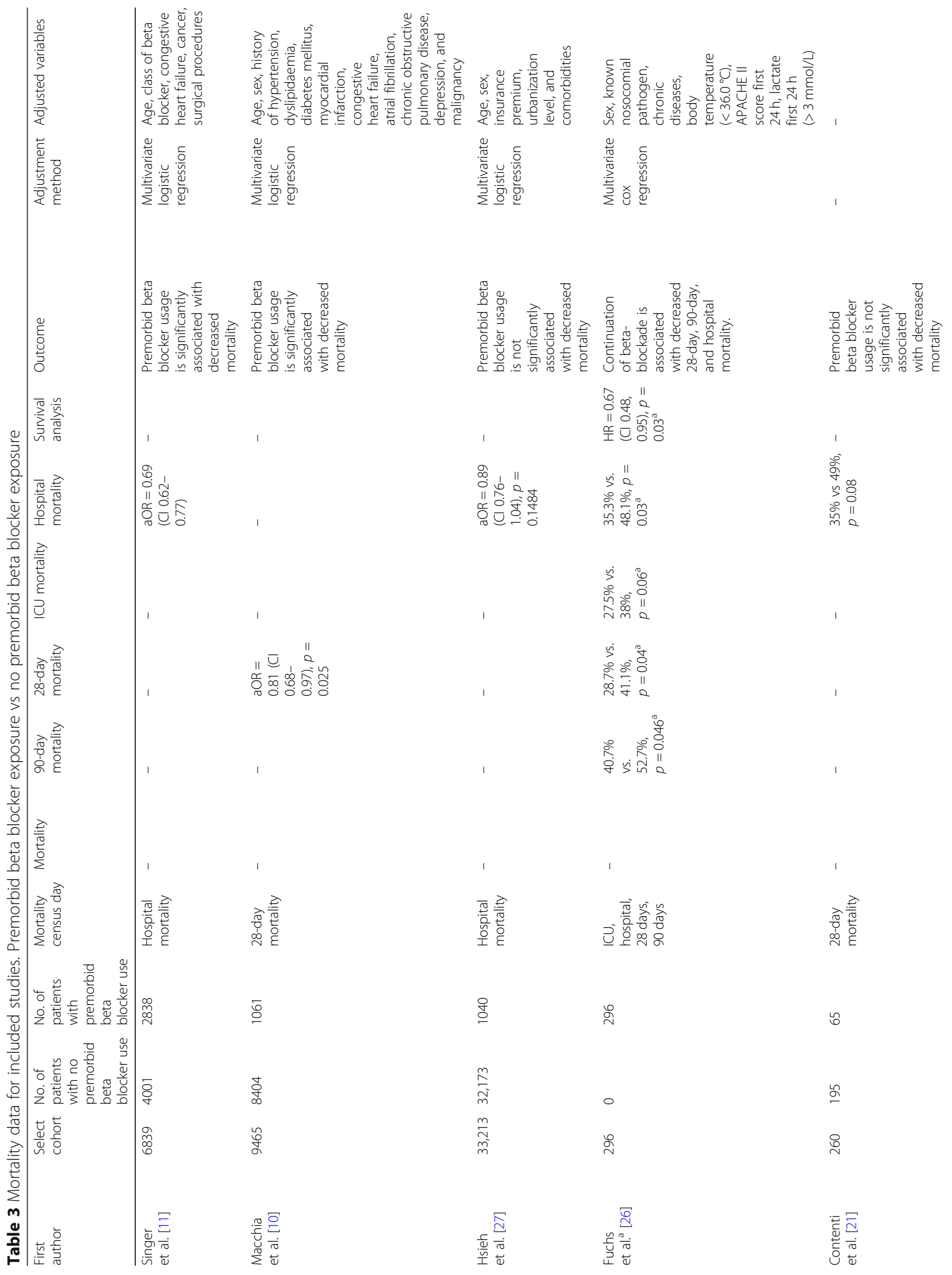


Tan et al. Critical Care $\quad$ (2019) 23:298

Page 7 of 12

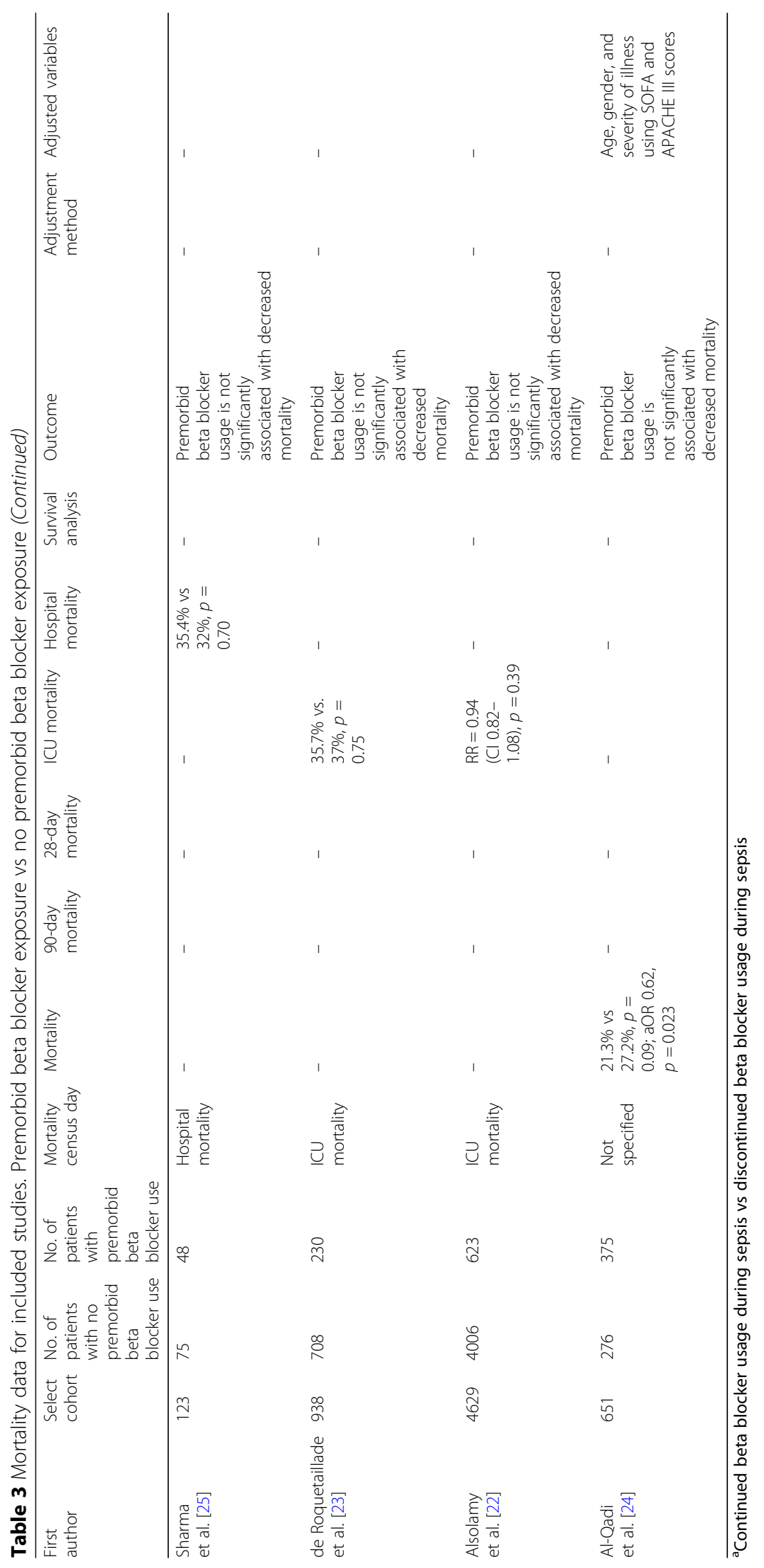


significantly higher mortality $(\mathrm{aOR}=1.16 ; 95 \%$ CI $[1.11,1.21] ; p<0.0001)$.

We compared the mortality data from the three studies that adjusted for potential confounders. Pooled analysis of the three studies showed an average odds ratio, $\mathrm{aOR}=0.79$; $95 \%$ CI $(0.67,0.92), p=0.004$; Fig. 2. However, there was substantial heterogeneity $\left(i^{2}=74 \%\right)$ between the studies, indicating that a meta-analysis is premature and that further studies and subgroup analyses are needed to validate the results.

Our systematic search also included grey literature in the form of conference abstracts. Mortality data from three studies reported as conference abstracts showed a trend towards a decrease in mortality with premorbid $\beta$ blocker exposure. However, the results were not statistically significant: de Roquetaillade et al. (ICU mortality; $35.7 \%$ vs. $37 \%, p=0.75$ ), Alsolamy et al. (ICU mortality; $\mathrm{RR}=0.94$ (CI: 0.82-1.08), $p=0.39$ ), and Al-Qadi et al. $(21.3 \%$ vs $27.2 \%, p=0.09)$ (Table 3$)$. Of note, the study by Alsolamy et al. included patients $\geq 14$ years old, while all other studies only included adults. Another retrospective study, reported as a conference abstract, involving 123 sepsis patients showed a non-significant increase in mortality with premorbid $\beta$-blocker exposure: Sharma et al. (hospital mortality; $35.4 \%$ vs $32 \%, p=0.70$; Table 3 ).

One interesting study by Fuchs et al. investigated the effect of continuing premorbid $\beta$-blocker use in patients with severe sepsis and septic shock. This study included 296 patients on chronic $\beta$-blockers, in which $\beta$-blockade was continued in 176 patients. Results showed that continuation of $\beta$-blockade during sepsis was associated with decreased 28 -day ( $28.7 \%$ vs. $41.1 \%, p=0.04)$, 90-day $(40.7 \%$ vs. $52.7 \%, p=0.046)$, and hospital mortality ( $35.3 \%$ vs. $48.1 \%, p=0.03$ ) (Table 3 ). Survival analysis also indicated that continuation of $\beta$-blockade during sepsis is significantly associated with decreased mortality $(\mathrm{HR}=0.67 ; 95 \% \mathrm{CI}[0.48,0.95] ; p=0.03$; Table 3$)$.

\section{Clinical parameters}

Only four studies by Contenti et al. [21], de Roquetaillade et al. [23], Sharma et al. [25], and Fuchs et al. [26] provided clinical parameter data. However, reporting of parameters was inconsistent. There was no significant difference in the requirements for vasopressor infusion across all four studies. Contenti et al. and de Roquetaillade et al. found that premorbid $\beta$-blocker exposure was associated with decreased heart rate; Sharma et al., did not report heart rate data. Continuation of $\beta$-blockade during sepsis was not associated with a decrease in heart rate in the first 24h [26]. Premorbid $\beta$-blocker use was found to be associated with lower initial plasma lactate levels by Contenti et al., but not by de Roquetaillade et al.. The continuation of $\beta$-blockade during sepsis was associated with lower plasma lactate levels in the first $24 \mathrm{~h}$ [26].

There were no significant differences in all other relevant parameters including mean arterial pressure, Sequential Organ Failure Assessment (SOFA) score, Acute Physiology and Chronic Health Evaluation (APACHE)-II or III score, and incidence of mechanical ventilation. The clinical parameter data are presented in Table 4.

\section{Discussion}

This is the first systematic review examining the role of premorbid $\beta$-blocker exposure on mortality outcomes in patients with sepsis. While there was not enough data to conduct a meta-analysis, pooled adjusted odds ratio from three studies indicated a potential decrease in mortality associated with premorbid $\beta$-blocker use, albeit with substantial heterogeneity. Our results provide preliminary evidence of a potential association between premorbid $\beta$-blocker use and mortality in sepsis and add to the emerging evidence suggesting harmful effects of adrenergic stress on mortality in sepsis. We discuss the effects of premorbid $\beta$-blocker exposure on the adrenergic response in early sepsis.

Cardiac dysfunction in sepsis is common and has both systolic and diastolic components [5]. However, only diastolic dysfunction seems to be associated with mortality $[28,29]$. While being on premorbid $\beta$ blockers may reduce systolic function, the reduction of adrenergic response in sepsis (decreasing heart rate, prolongation of diastolic time, and improved coronary perfusion) can lead to mitigation of diastolic dysfunction [28, 29]. Further, the risks of myocardial ischemia may be decreased due to reduced myocardial oxygen consumption [14].

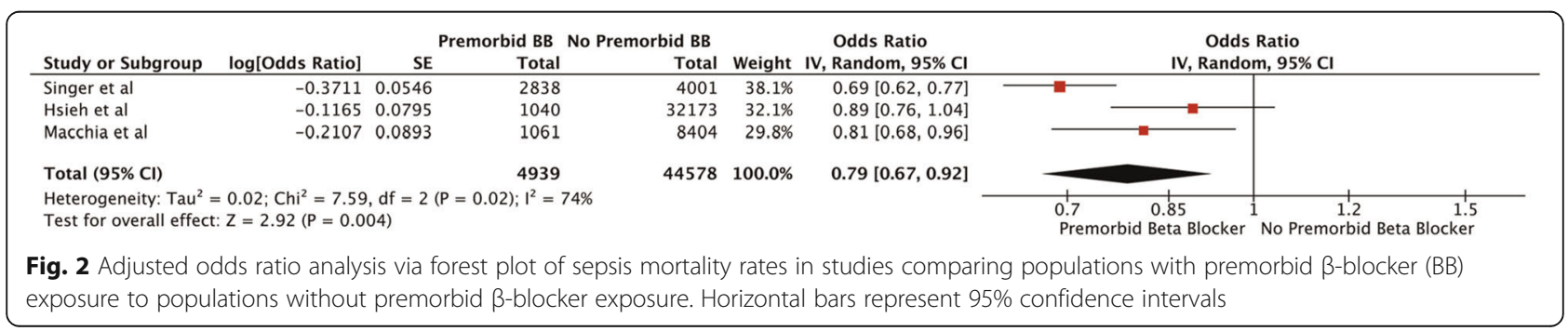




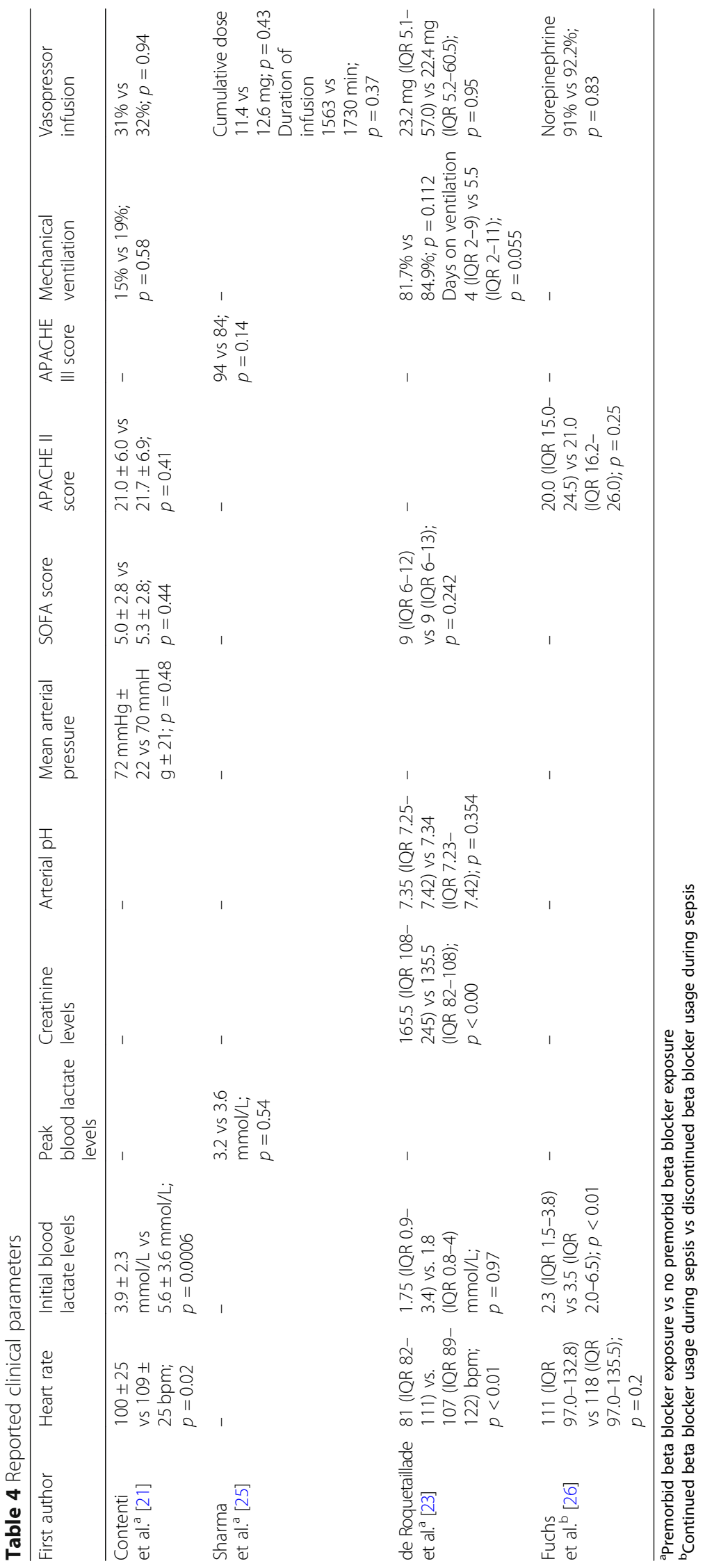


Patients with septic shock are often treated with large doses of exogenous catecholamines for haemodynamic stabilization. The most recent Surviving Sepsis Campaign guidelines recommend using noradrenaline as the firstline agent for vasopressor therapy, with adrenaline or lowdose vasopressin as second-line agents [4]. Increased dosage and duration of noradrenaline administration has been associated with higher incidence of new onset atrial fibrillation [3]. Excessive catecholamine levels may also play an important role in sepsis-related cardiac dysfunction by causing cardiomyopathy and cardiomyocyte necrosis [5, 7]. $\beta$-adrenergic blockade could reduce the amount of exogenous catecholamines used by restoring sepsis-induced downregulation of $\beta$-adrenergic receptors $[12,30]$. Four of the included studies in this systematic review, however, found that premorbid $\beta$-blocker exposure was not associated with a significant difference in vasopressor requirements during sepsis. Similarly, Fuchs et al. found that continuing chronic beta blockers during acute phase of sepsis is not associated with increased use of catecholamines.

Interestingly, Singer et al. reported that patients with premorbid exposure to non-selective $\beta$-blockers had lower mortality rates compared to patients with premorbid cardioselective $\beta$-blocker exposure [11]. This suggests that $\beta$-blocker modulation of non-cardiac adrenergic responses to sepsis may also have an important role. Furthermore, $\beta$-blockers may potentially positively modulate the disturbed autonomic (sympatheticparasympathetic) balance in sepsis [31].

Adrenergic response to sepsis induces a hypermetabolic state characterized by increased energy expenditure, hyperglycaemia, lipolysis and proteolysis, supressed ketogenesis, and negative nitrogen balance resulting in eventual loss of lean body mass [32]. $\beta 2$-adrenergic blockade appears to have the potential to reverse hyperglycaemia and reduce proteolysis [7]. For example, the use of propranolol in children with severe burns appears to attenuate hypermetabolism and reverse muscle catabolism [33].

The immune system is also modulated by the adrenergic responses to sepsis [34]. The $\beta$-adrenergic system regulates apoptosis, mitochondrial function, and inflammatory cytokine production. $\beta$-blockers influence the pattern of cytokine synthesis with $\beta 1$ blockers downregulating a proinflammatory response, whereas $\beta 2$-antagonization seems to have an opposite effect, at least in chronic heart failure [35].

In sepsis, $\beta 2$-adrenergic stimulation selectively inhibits $\mathrm{CD} 44^{+}$lymphocyte Th1 function and favours the Th2 responses that inhibit macrophage activation, $\mathrm{T}$ cell proliferation, and proinflammatory cytokine production [7]. $\mathrm{CD}^{+}$lymphocyte function may also be suppressed by $\beta 2$-adrenergic stimulation [36]. The derangement in lymphocytic function induced by catecholamines is thus reminiscent of sepsis-induced immune suppression and could even be considered as one of the mechanisms. However, to date, the evidence for any beneficial use of $\beta$-adrenergic blockade on immune function in sepsis has been conflicting [7].

Sepsis results in a pro-thrombotic state with increases in plasma tissue factor and von Willebrand factor levels [37]. Platelets also express adrenergic receptors on their surface [38]. However, there are conflicting effects of $\beta 1$ and $\beta 2$ pathways on platelet function [7]. The use of $\beta$ adrenergic blockade led to decreased endothelial cell damage in a murine model of shock coagulopathy [39]. This suggests that premorbid $\beta$-blocker therapy might mitigate shock-induced endotheliopathy (SHINE), attenuating sepsis-associated coagulopathy [40].

Nonetheless, multiple questions on the role of $\beta$-adrenergic blockade in sepsis remain unanswered. On top of safety and efficacy concerns, the duration and dosage at which $\beta$-blockade should be performed remain to be elucidated. Furthermore, the timing of therapeutic $\beta$-adrenergic blockade initiation is also controversial. The results of our systematic review suggest that we should not discount $\beta$-blockers during sepsis. Instead, we may consider continuing chronic $\beta$-blockers and perhaps introduce $\beta$-blocking drugs early in the sepsis management, especially the non-cardioselective ones.

\section{Strengths and limitations}

This study analysed data from nine observational studies, four of which were reported as conference abstracts. There was not enough data to conduct a meta-analysis. By nature of observational studies, systematic confounding and risk of bias cannot be ruled out. The risk of bias can be reduced by adjusted analysis. Analysis of pooled adjusted odds ratio revealed a significant decrease in sepsis mortality with premorbid $\beta$-blocker exposure, but adjusted data were available only from three studies. Despite the three studies providing data on the majority of patients included in this review, substantial heterogeneity is present and residual confounding is likely. Potential sources of confounding include the variable definitions of premorbid $\beta$-blocker exposure used by the included studies, the appropriate prescription of $\beta$-blockers to all included patients, and patient compliance to treatment.

The conclusions that can be drawn from this study are also hampered by the lack of clinical parameter data, limiting our ability to decipher the likely mechanism/s by which premorbid $\beta$-blocker exposure may lower sepsis mortality.

\section{Conclusion}

This systematic review suggests that $\beta$-blocker exposure prior to an episode of sepsis could have a role in reducing sepsis mortality. More evidence, however, is needed 
to elucidate whether premorbid $\beta$-blocker treatment is able to mitigate, and by what mechanism, the potentially detrimental effects of endogenous or exogenous catecholamines in early sepsis. Further appropriately powered and ideally prospective observational studies on premorbid $\beta$-blocker exposure will be necessary to generate the required evidence.

\section{Additional files}

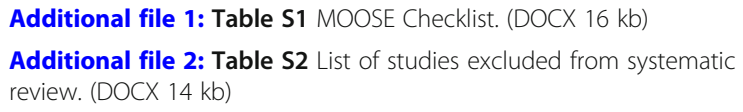

Additional file 3: Table S3 Reasoning for Bias Assessment for Mortality Outcome using ROBINS-1 Tool (DOCX 18 kb)

Additional file 4: Figure S1 Detailed search strategy. (DOCX 13 kb)

Additional file 5: Figure S2 Risk of bias assessment for mortality in individual studies using ROBINS-I assessment tool. (TIF 1123 kb)

\section{Abbreviations}

aOR: Adjusted odds ratio; APACHE: Acute Physiology and Chronic Health Evaluation; Cl: Confidence interval; ED: Emergency department; HR: Hazard ratio; ICU: Intensive care unit; MOOSE: Meta-analysis Of Observational Studies in Epidemiology; PICOS: Patient, Population, or Problem, Intervention, Comparison, Outcome, Study Design or Setting; PROSPERO: International prospective register of systematic reviews; ROBINS-I: Risk Of Bias In Nonrandomized Studies - of Interventions; RR: Relative risk; SHINE: Shock-induced endotheliopathy; SOFA score: Sequential Organ Failure Assessment

\section{Acknowledgements}

Not applicable.

\section{Authors' contributions}

$\mathrm{KQ}$ and $\mathrm{MN}$ designed the study. $\mathrm{KQ}, \mathrm{MH}$, and $\mathrm{MN}$ conducted the literature search and data analysis. KQ drafted the manuscript. $\mathrm{MH}, \mathrm{BT}, \mathrm{AM}$, and MN revised the manuscript. All authors read and approved the final manuscript.

\section{Funding}

Nepean Institute of Critical Care Education and Research (NICCER). Dr. Nalos and Dr. Harazim were was supported by the Charles University Research Fund (project number Q39) and by project number CZ.02.1.01/0.0/.0/16_019/ 0000787 'Fighting Infectious Diseases,' awarded by the Ministry of Youth and Education Services of the Czech Republic.

\section{Availability of data and materials}

Not applicable.

\section{Ethics approval and consent to participate}

Ethics approval for systematic review is not required.

\section{Consent for publication}

Not applicable.

\section{Competing interests}

The authors declare that they have no competing interests.

\section{Author details}

${ }^{1}$ Nepean Clinical School, Sydney Medical School, University of Sydney, Penrith, Australia. 'Department of Intensive Care Medicine, Nepean Hospital, Penrith, Australia. ${ }^{3}$ Centre for Immunology and Allergy Research, Westmead Millennium Institute, Westmead, Australia. ${ }^{4}$ Medical Intensive Care Unit, Teaching Hospital and Biomedical Centre, Charles University, Alej Svobody 80, 32300 Pilsen, Czech Republic.
Received: 29 April 2019 Accepted: 7 August 2019

Published online: 04 September 2019

\section{References}

1. Singer M, Deutschman CS, Seymour CW, Shankar-Hari M, Annane D, Bauer $M$, et al. The third international consensus definitions for sepsis and septic shock (Sepsis-3). JAMA. 2016;315(8):801 [cited 2018 Jun 14]. Available from: http://jama.jamanetwork.com/article.aspx?doi=10.1001/jama.2016.0287.

2. Gotts JE, Matthay MA. Sepsis: pathophysiology and clinical management. BMJ [Internet. 2016:i1585 [cited 2019 Mar 24]. Available from: http://www. bmj.com/lookup/doi/10.1136/bmj.i1585.

3. Lesur O, Delile E, Asfar P, Radermacher P. Hemodynamic support in the early phase of septic shock: a review of challenges and unanswered questions. Ann Intensive Care. 2018;8(1) [cited 2019 Mar 24]. Available from: https://annalsofintensivecare.springeropen.com/articles/10.1186/s13613-0180449-8.

4. Rhodes A, Evans LE, Alhazzani W, Levy MM, Antonelli M, Ferrer R, et al. Surviving sepsis campaign: international guidelines for management of sepsis and septic shock: 2016. Intensive Care Med. 2017:43(3):304-77 [cited 2019 Mar 25]. Available from: http://link.springer.com/10.1007/s00134-017-46 83-6.

5. Suzuki T, Suzuki Y, Okuda J, Kurazumi T, Suhara T, Ueda T, et al. Sepsisinduced cardiac dysfunction and $\beta$-adrenergic blockade therapy for sepsis. J Intensive Care. 2017;5(1) [cited 2019 Mar 24]. Available from: http:// jintensivecare.biomedcentral.com/articles/10.1186/s40560-017-0215-2.

6. Singer M. Catecholamine treatment for shock-equally good or bad? Lancet. 2007;370(9588):636-7 [cited 2019 Mar 25]. Available from: https:// linkinghub.elsevier.com/retrieve/pii/S0140673607613178.

7. de Montmollin E, Aboab J, Mansart A, Annane D. Bench-to-bedside review: $\beta$-adrenergic modulation in sepsis. Crit Care. 2009;13(5):230 [cited 2019 Mar 25]. Available from: http://ccforum.biomedcentral.com/articles/10.1186/ cc8026.

8. Morelli A, Ertmer C, Westphal M, Rehberg S, Kampmeier T, Ligges S, et al. Effect of heart rate control with esmolol on hemodynamic and clinical outcomes in patients with septic shock: a randomized clinical trial. JAMA. 2013;310(16):1683 [cited 2018 Jun 21]. Available from: http://jama. jamanetwork.com/article.aspx?doi=10.1001/jama.2013.278477.

9. Morelli A, Donati A, Ertmer C, Rehberg S, Kampmeier T, Orecchioni A, et al. Microvascular effects of heart rate control with esmolol in patients with septic shock: a pilot study*. Crit Care Med. 2013;41(9):2162-8 [cited 2019 Mar 24]. Available from: https://insights.ovid.com/crossref?an=00003246-2 01309000-00011.

10. Macchia A, Romero M, Comignani PD, Mariani J, D'Ettorre A, Prini N, et al. Previous prescription of $\beta$-blockers is associated with reduced mortality among patients hospitalized in intensive care units for sepsis*. Crit Care Med. 2012;40(10):2768-72 [cited 2019 Mar 17]. Available from: https:// insights.ovid.com/crossref?an=00003246-201210000-00004.

11. Singer KE, Collins CE, Flahive JM, Wyman AS, Ayturk MD, Santry HP. Outpatient beta-blockers and survival from sepsis: results from a national cohort of Medicare beneficiaries. Am J Surg. 2017;214(4):577-82 [cited 2019 Mar 17]. Available from: https://linkinghub.elsevier.com/retrieve/pii/S0002961 017302891.

12. van Loon LM, van der Hoeven JG, Lemson J. Hemodynamic response to $\beta$ blockers in severe sepsis and septic shock: a review of current literature. J Crit Care. 2019:50:138-43 [cited 2019 Mar 24]. Available from: https:// linkinghub.elsevier.com/retrieve/pii/S0883944118310566.

13. Chacko C, Gopal S. Systematic review of use of $\beta$-blockers in sepsis. J Anaesthesiol Clin Pharmacol. 2015;31(4):460 [cited 2019 Mar 24]. Available from: http://www.joacp.org/text.asp?2015/31/4/460/169063.

14. Sanfilippo F, Santonocito C, Morelli A, Foex P. Beta-blocker use in severe sepsis and septic shock: a systematic review. Curr Med Res Opin. 2015; 31(10):1817-25 [cited 2019 Mar 24]. Available from: http://www.tandfonline. com/doi/full/10.1185/03007995.2015.1062357.

15. McLean AS, Taccone FS, Vieillard-Baron A. Beta-blockers in septic shock to optimize hemodynamics? No. Intensive Care Med. 2016;42(10):1610-2 [cited 2019 Mar 28]. Available from: http://link.springer.com/10.1007/s00134-016-44 07-3.

16. Stroup DF. Meta-analysis of observational studies in epidemiology: a proposal for reporting. JAMA. 2000;283(15):2008 [cited 2018 Jul 30]. Available from: http://jama.jamanetwork.com/article.aspx?doi=10.1001/ jama.283.15.2008. 
17. Liberati A, Altman DG, Tetzlaff J, Mulrow C, Gøtzsche PC, loannidis JPA, et al. The PRISMA statement for reporting systematic reviews and meta-analyses of studies that evaluate health care interventions: explanation and elaboration. PLoS Med. 2009;6(7):e1000100 [cited 2018 Aug 11]. Available from: http://dx.plos.org/10.1371/journal.pmed.1000100.

18. Sterne JA, Hernán MA, Reeves BC, Savović J, Berkman ND, Viswanathan M, et al. ROBINS-I: a tool for assessing risk of bias in non-randomised studies of interventions. BMJ. 2016:14919 [cited 2018 Jul 30]. Available from: http:// www.bmj.com/lookup/doi/10.1136/bmj.i4919.

19. Park S, Beretvas SN. Using total sample size weights in meta-analysis of logodds ratios. J Exp Educ. 2018;1-15. [cited 2019 Mar 25]. Available from: https://www.tandfonline.com/doi/full/10.1080/00220973.2018.1451295

20. Higgins JPT, Thompson SG. Quantifying heterogeneity in a meta-analysis. Stat Med. 2002;21(11):1539-58 [cited 2018 Jul 2]. Available from: http://doi. wiley.com/10.1002/sim.1186.

21. Contenti J, Occelli C, Corraze H, Lemoël F, Levraut J. Long-term $\beta$-blocker therapy decreases blood lactate concentration in severely septic patients* Crit Care Med. 2015;43(12):2616-22 [cited 2019 Mar 17]. Available from: https://insights.ovid.com/crossref?an=00003246-201512000-00012.

22. Alsolamy S, Ghamdi G, Alswaidan L, Alharbi S, Alenezi F, López-Rodríguez M, et al. 36th International Symposium on Intensive Care and Emergency Medicine: Brussels, Belgium. 15-18 March 2016. Crit Care. 2016;20(S2) [cited 2019 Mar 17]. Available from: http://ccforum.biomedcentral.com/articles/1 0.1186/s13054-016-1208-6.

23. de Roquetaillade C, Llitjos J-F, Jamme M, Charpentier J, Cariou A, Chiche J-D, et al. Proceedings of Réanimation 2018, the French Intensive Care Society International Congress. Ann Intensive Care. 2018;8(S1) [cited 2019 Mar 17]. Available from: https://annalsofintensivecare.springeropen.com/articles/10.11 86/s13613-017-0345-7.

24. Al-Qadi MO, O'Horo JC, Thakur L, Kaur S, Berrios RAS, Caples SM, et al. Longterm use of beta blockers is protective in severe sepsis and septic shock. In: American Journal of Respiratory and Critical Care Medicine. San Diego: Conference: Ameriacn Thoracic Society International Conference, ATS 2014; 2014. p. 189.

25. Sharma A, Vashisht R, Bauer S, Hanane T. Effect of preadmission betablocker use on outcomes of patients admitted with septic shock. United States: Critical Care Medicine; 2016. p. 413.

26. Fuchs C, Wauschkuhn S, Scheer C, Vollmer M, Meissner K, Kuhn S-O, et al. Continuing chronic beta-blockade in the acute phase of severe sepsis and septic shock is associated with decreased mortality rates up to 90 days. $\mathrm{Br} J$ Anaesth. 2017;119(4):616-25 [cited 2018 Jun 21]. Available from: http:// linkinghub.elsevier.com/retrieve/pii/S000709121753799X.

27. Hsieh M-S, How C-K, Hsieh VC-R, Chen P-C. Preadmission antihypertensive drug use and sepsis outcome: impact of angiotensin-converting enzyme inhibitors (ACEls) and angiotensin receptor blockers (ARBs). Shock. 2019;1 [cited 2019 Jun 22]. Available from: http://Insights.ovid.com/crossref?an= 00024382-900000000-97629.

28. Sanfilippo F, Corredor C, Fletcher N, Landesberg G, Benedetto U, Foex P, et al. Diastolic dysfunction and mortality in septic patients: a systematic review and meta-analysis. Intensive Care Med. 2015;41(6):1004-13 [cited 2019 Mar 25]. Available from: http://link.springer.com/10.1007/s00134-015-3748-7.

29. Sanfilippo F, Corredor C, Arcadipane A, Landesberg G, Vieillard-Baron A, Cecconi $M$, et al. Tissue Doppler assessment of diastolic function and relationship with mortality in critically ill septic patients: a systematic review and meta-analysis. Br J Anaesth. 2017;119(4):583-94 [cited 2019 Jun 15]. Available from: https://linkinghub.elsevier.com/retrieve/pii/ S0007091217537964.

30. Kimmoun A, Louis H, Al Kattani N, Delemazure J, Dessales N, Wei C, et al. $\beta 1$-adrenergic inhibition improves cardiac and vascular function in experimental septic shock*. Crit Care Med. 2015;43(9):e332-40 [cited 2019 Mar 26]. Available from: https://insights.ovid.com/crossref?an=00003246-2 01509000-00044

31. Kohoutova M, Horak J, Jarkovska D, Martinkova V, Tegl V, Nalos L, et al. Vagus nerve stimulation attenuates multiple organ dysfunction in resuscitated porcine progressive sepsis. Crit Care Med. 2019;1 [cited 2019 Apr 19]. Available from: http://Insights.ovid.com/crossref?an=00003246900000000-95985.

32. Chioléro R, Revelly JP, Tappy L. Energy metabolism in sepsis and injury. Nutr Burbank Los Angel Cty Calif. 1997;13(9 Suppl):45S-51S.

33. Herndon DN, Hart DW, Wolf SE, Chinkes DL, Wolfe RR. Reversal of catabolism by beta-blockade after severe burns. N Engl J Med. 2001;345(17):
1223-9 [cited 2019 Mar 26]. Available from: http://www.nejm.org/doi/abs/1 0.1056/NEJMoa010342.

34. Elenkov IJ, Wilder RL, Chrousos GP, Vizi ES. The sympathetic nerve--an integrative interface between two supersystems: the brain and the immune system. Pharmacol Rev. 2000;52(4):595-638.

35. Shaw SM, Coppinger T, Waywell C, Dunne L, Archer LD, Critchley WR, et al. The effect of beta-blockers on the adaptive immune system in chronic heart failure. Cardiovasc Ther. 2009;27(3):181-6 [cited 2019 Apr 19]. Available from: http://doi.wiley.com/10.1111/j.1755-5922.2009.00089.x.

36. Estrada LD, Ağaç D, Farrar JD. Sympathetic neural signaling via the $\beta 2$ adrenergic receptor suppresses T-cell receptor-mediated human and mouse CD8 ${ }^{+}$T-cell effector function. Eur J Immunol. 2016;46(8):1948-58 [cited 2019 Apr 4]. Available from: http://doi.wiley.com/10.1002/eji.201646395.

37. Schouten $M$, Wiersinga WJ, Levi M, van der Poll T. Inflammation, endothelium, and coagulation in sepsis. J Leukoc Biol. 2008:83(3):53645 [cited 2019 Mar 26]. Available from: http://doi.wiley.com/10.1189/ jlb.0607373.

38. Hjemdahl P, Larsson PT, Wallén NH. Effects of stress and beta-blockade on platelet function. Circulation. 1991;84(6 Suppl):Vl44-61.

39. Xu L, Yu W-K, Lin Z-L, Tan S-J, Bai X-W, Ding K, et al. Chemical sympathectomy attenuates inflammation, glycocalyx shedding and coagulation disorders in rats with acute traumatic coagulopathy. Blood Coagul Fibrinolysis. 2015;26(2):152-60 [cited 2019 Apr 28]. Available from: https://insights.ovid.com/crossref?an=00001721-201503000-00006.

40. Johansson P, Stensballe J, Ostrowski S. Shock induced endotheliopathy (SHINE) in acute critical illness - a unifying pathophysiologic mechanism. Crit Care. 2017;21(1):25 [cited 2019 Apr 28]. Available from: http://ccforum. biomedcentral.com/articles/10.1186/s13054-017-1605-5.

\section{Publisher's Note}

Springer Nature remains neutral with regard to jurisdictional claims in published maps and institutional affiliations.

Ready to submit your research? Choose BMC and benefit from:

- fast, convenient online submission

- thorough peer review by experienced researchers in your field

- rapid publication on acceptance

- support for research data, including large and complex data types

- gold Open Access which fosters wider collaboration and increased citations

- maximum visibility for your research: over $100 \mathrm{M}$ website views per year

At BMC, research is always in progress.

Learn more biomedcentral.com/submissions 